\title{
DEBATE \\ COMENTÁRIOS SOBRE UM TEXTO DE BRUNO LATOUR
}

Otávio Velho

\begin{abstract}
Esta é uma seção dedicada ao comentário de textos publicados em números anteriores de Mana. Estudos de Antropologia Social. O texto a seguir referese - mais diretamente - ao artigo de Bruno Latour, "'Não congelarás a imagem', ou: como não desentender o debate ciência-religião", publicado em Mana, 10(2), 2004.
\end{abstract}

Em livro de entrevistas que Bruno Latour realizou com Michel Serres (Serres 1999 [1992]), este autor faz a defesa da solidão no trabalho filosófico. Latour, por seu lado, contrapõe-se e pergunta por que Serres não se reconhece como integrante de um conjunto de discussões e sequer cita os colegas (1999 [1992]:109-110). Serres, então, declara seu repúdio à era da tese, do jornal e da gagueira: "A honestidade, pelo contrário, consiste em só escrever o que se pensa e que se acredita ter inventado" (1999[1992]:110). Curiosamente, alguns anos mais tarde, em Jubiler ou les tourments de la parole religieuse (2002a), Latour dá a impressão (não totalmente exata, como veremos) de aderir ao mestre, até mesmo antecipando-se a este para realizar a obra de síntese que exige a abdicação de tudo o que se sabe para que se possa, enfim, inventar, e que Serres apresentava nas entrevistas como um ideal, ainda posto no futuro. Futuro que ele tinha pressa em alcançar. A (des)organização de Jubiler é sintomática: nenhuma citação, nenhuma nota, nem ao menos capítulos, mas um estilo bem afinado para servir à argumentação. A ponto de por vezes parecerem simples, assuntos que são altamente complexos, que na verdade desafiam e fazem duvidar se de fato nossa leitura é capaz de alcançar todas as nuances.

Há uma série de intuições pontuais de Serres, que certamente inspiraram Latour a dialogar com ele implicitamente e, assim, desenvolver seu próprio pensamento (como no caso do fetiche, do interesse pelos tribunais, da relação entre Sócrates e Górgias e do contraste entre a multiplicidade 
das culturas e uma natureza supostamente única). Pois apesar disso, e de continuarem a compartilhar, Serres e Latour, a aposta num reencontro (ou em um novo contrato) entre humanos e não-humanos e no que Latour denominava, em certo momento, naturezas-culturas, ele consolida em Jubiler diferenças significativas em relação a Serres. Diferenças que vão além da já evidente descrença nas rupturas, contrastante com as posições do autor de Hominescências (Serres 2003[2001]) — ode a uma nova humanidade, publicada originalmente em 2001 e que é praticamente contemporânea de Jubiler. Latour insiste nos limites da comunicação, no entanto central para Serres, desde muito antes, na figura de Hermes, erigido em patrono; e insiste também na distinção, a partir desses limites, entre os regimes de enunciação, quando em Serres, ao contrário, as articulações entre filosofia, literatura e ciência constituem um ponto de partida. Isso, apesar de o regime de enunciação do próprio Jubiler dar a impressão de estar no caminho da busca de uma fusão entre literatura e ciências sociais (contanto que não se pretendam "críticas"), sem falar da teologia. A insistência na distinção entre regimes de enunciação, ao que parece, seria parte de uma estratégia de defesa contra o cientificismo; ou seja, defesa contra a penetração e paralisia da política (e não só, como veremos) pela Ciência (no singular), com a politização clandestina das ciências (no plural) pela epistemologia, a que corresponderia uma Natureza igualmente singular (Latour 2004[1999]). Enquanto Serres reclama do banimento da natureza, Latour reclama de sua invenção. Crítica, por sua vez, é palavra banida, já que associada à modernidade, à ruptura e, sobretudo, a Kant e à concepção de uma "revolução copernicana" que nos separa do passado: o esforço é por tornar-se cada vez menos crítico, aceitando a vida como ela é, de um modo que lembra (além de Nelson Rodrigues) o amor fati nietzschiano.

Não se pode dizer, porém, que Jubiler constitua uma culminância, única, apesar de o título aparentemente referir-se à proclamação por Jesus da chegada do Reino de Deus (Lucas 4:15-22). Talvez porque essa expressão se inspire, por sua vez, no ano jubilar anunciado no Levítico (25:8-17), que deveria ser periódico. Estamos, de fato, diante de uma intertextualidade que (como no caso presente) dificulta, inclusive, o isolamento de qualquer dos elementos da cadeia. Os argumentos expostos estão ativos, antes e depois, em outros textos e de outras maneiras, constituindo-se, pois, Jubiler em uma elevação particularmente saliente em um caminho que, no entanto, prossegue, como num jubileu que sugere outros - parte de uma produção que espanta tanto pela qualidade, quanto pela quantidade. No próprio ano de 2002, por exemplo, além de Jubiler, Latour publicou outro livro significativo, La fabrique du droit: une ethnographie du Conseil d'État (2002b). 
Trata-se, portanto, de reconhecer-lhe a saliência, mas ao mesmo tempo, aqui também, seu pertencimento a um conjunto. Conjunto que se articula, mas também se diferencia dos seus escritos anteriores sobre a prática científica; e que tem na religião o seu desafio maior. Entre os dois conjuntos coloca-se (entre outros) Jamais fomos modernos (1994 [1991]), seu livro mais conhecido, que os interliga por intermédio da problemática onipresente da (não-)modernidade e da política.

O texto publicado no número anterior de Mana pertence a esse segundo grupo, bem diferente, e do qual, no entanto, a ciência não está ausente. Pelo contrário, está presente, ainda que, por vezes, fantasmaticamente, sobretudo devido à contraposição privilegiada que a religião permite fazer ao discurso da Ciência; pois urge tentar contornar a pretensão desse discurso a deter o monopólio da razão ou a servir de paradigma exclusivo. Daí a insistência em não aceitar que a religião seja vista como uma razão de segunda classe (a crença), quando comparada com a ciência. Mas daí também a negação de que a religião tenha a ver com a transmissão de informação. Como é dito naquele texto, é preciso mapear as condições de felicidade dos diferentes regimes de enunciação, ou seja, das várias atividades que em nossa cultura são capazes de evocar a verdade; como é o caso também da política, que, do mesmo modo que a religião, precisa ser distinguida e resgatada do paradigma científico, paralisante para ela. No texto aqui publicado, é explícita a presença da ciência, bem como - e eis uma originalidade - a do pragmatismo filosófico, quiçá muito mais ativo no conjunto de sua obra do que fazem supor as menções (nem tão freqüentes) a William James e John Dewey. Pragmatismo ativo até no distanciamento em relação à dominância das análises de discurso que se fazem em detrimento das práticas - o que o distingue, por vezes, do neopragmatismo, linguajeiro. Em Latour, discurso e prática podem (de novo) se contrapor, como no caso - mas não só — do discurso oficial da modernidade, que se opõe a, ou mesmo denega, as práticas oficiosas. E reconhecê-lo não deixa de ser mais uma forma de se distanciar da dominância do discurso da Ciência, que propugna sempre a "transparência", incompatível com essa contraposição, que ele não reconhece.

Curiosamente, a insistência na distinção entre os regimes de enunciação tende de certo modo a lembrar mais a purificação moderna, que Latour renega, do que a mistura não-moderna, à qual procura se associar. Proximidade da purificação, ainda que a referida distinção não impeça o espraiamento e disseminação dos regimes, não correspondendo a eles as esferas ou domínios próprios da política, da economia, do social, do direito, da ciência ou da religião. Talvez não seja sem conseqüência que essa 
distinção lembre Foucault, que o próprio Latour associa, em contraste com ele mesmo, à descontinuidade e à ruptura. Por outro lado, é de se perguntar por que não aderir a uma imagem mais generosa da comunicação, que poderia ser reconhecida sem identificação com a do cientificismo, como na figura de Hermes segundo o próprio Serres: agitado, desordeiro, errante, alegre. Hermes mensageiro e músico, que sobrepuja o Argos da vigilância e da teoria; deus do comércio, pai da comédia, que descreve a circulação de todas as coisas; deus do cruzamento, dos ladrões, do segredo e do riso. Ou, de outro modo, por que não aderir aos anjos, às "preposições de Deus", anunciados por Hermes e que em sua multiplicidade coroam o espaçotempo da comunicação e estes tempos do universo informacional, reconciliando a ciência e a técnica com a religião?

Serres também reclama da informação. Mas da informação que substitui o conhecimento. Para ele, o "mensageiro traz sempre estranhas notícias, ou não passa de um papagaio" (1999 [1992]:89); e somente a criação distingue o bem do mal. Em Latour, não é bem esse o problema. Ele é contra a onipresença do próprio conhecimento: a religião, insiste, não é uma gnose; apesar de não ser tampouco uma crença — respeitável, porém não razoável - sobre assuntos distantes, e que é tolerada hipocritamente. Embora, é bem verdade, Latour pareça manter aí uma ambigüidade, exposta no fato de ele ora reclamar da informação genericamente, ora qualificá-la (em uma referência irônica à operação do mouse do computador) como informação duplo-clique, uma informação que pretenderia um transporte sem deformação. Pretensão que, em outros textos (como o que foi aqui publicado), Latour não considera adequada sequer para descrever a prática real das ciências, mas apenas o discurso da Ciência. O mesmo ocorre no caso do referente externo, utilizado para marcar por ausência regimes de enunciação como o da religião; mas sendo que, no final das contas, até nas ciências Latour o substitui pela referência circulante, a seqüência potencialmente infinita de mediadores, que, na verdade, substitui a oposição entre o externo e o interno. É impossível exigir uma informação direta quando se está na dependência de laboratórios, instrumentos, equipamentos, manipulação de dados, escrita, congressos, orçamentos, disputas etc. A ênfase é nas mediações e nos mediadores (distinguindo-se, porém, os seus modos de disposição e rebatimento) e a informação nunca é simplesmente transferida, pagando por seu transporte um encargo pesado em transformações, mesmo que mantendo uma constante no caso das ciências em ação.

E, no entanto, a distinção entre os regimes de enunciação continua necessária para a argumentação de Latour; especialmente a distinção entre a ênfase na transferência de informação própria da ciência e, inversamente 
(sobretudo quando se trata de religião), a ênfase na presentificação, na produção da pessoa, na re-presentação, evidentemente próximas à noção grega de parousia transliterada pelo cristianismo para referir-se privilegiadamente à segunda vinda de Cristo. É preciso proteger-nos contra a possibilidade de uma equivalência geral, buscando, ao invés, uma "nãoequivalência generalizada", sugere ele numa entrevista (Crawford 1993). O temor principal, aparentemente, é que qualquer concessão ao cientificismo venha a ser fatal. Distanciando-se do paradigma da informação, a política teria a ver com a formação de grupos. A religião, por sua vez, teria a ver com a transformação (utilizando-se, no texto ora comentado, a conversação amorosa para ilustrá-la); ou, na linguagem de uma tradição que Latour assume, teria a ver com a conversão. A religião não se referiria a um além, e sim ao "aqui e agora". Curiosamente, essas transformação e conversão radicais, súbitas e absolutas, baseadas no modelo paulino, são as mesmas que têm sido postas em dúvida, quanto a sua abrangência, por estudos de antropologia da religião. Postas em dúvida, sobretudo, em terrenos não-ocidentais (mas ainda tendo a ver com o cristianismo global), que fazem reclamar da não aplicabilidade do modelo paulino em casos que apareceriam, diante dele, como incompletos ou mesmo falsos - aliás, de modo ironicamente análogo ao que Latour reclama quando da referência de outros regimes de enunciação à ciência. Não seria aberto aqui, por Latour, espaço sequer para os hibridismos, que em ou-tros contextos ele valoriza. Mas se, em outros tempos, ele poderia ser interpelado em seu cristianocentrismo, hoje a questão se coloca no campo mesmo do cristianismo, materializada sobretudo na luta surda entre o Vaticano e as variadas manifestações cristãs no Terceiro Mundo.

A argumentação de que o cientificismo (a Ciência) é o inimigo principal (tomando-se o termo inimigo em um sentido diferente do que lhe dá o próprio Latour, cujo glossário não conhece nem limites, nem estabilização) é impactante. No caso da política, faz (re)pensar a propriedade das demandas por transparência e coerência que têm ganhado força renovada entre nós, juntamente com boa dose de hipocrisia. Hipocrisia exigida, segundo essa linha de argumentação, justamente pela dominância do cientificismo, que se dá em terreno que não é o dele, constituindo-se um verdadeiro duplo-vínculo que impede a formulação de regras próprias e legítimas para a política e que faz com que a prática se revista de um cunho de selvageria (o ganho financeiro - pode-se supor - representando como que a face obscura da lógica do equivalente geral). A eficácia que o cientificismo aí conquista no longo prazo seria paralisante e incompatível com as finalidades agregadoras e de gestão do Estado (Latour s/d). Argumentação 
impactante, ainda, devido à dificuldade que todos já temos de pensar em outros moldes, e de relembrar, por exemplo, a tradição maquiavélica, que também é - e não por acaso - denegrida, assim como outra tradição a ela aparentada, a de Espinosa, que duvida e faz duvidar da separação hobbesiana entre o estado de natureza e o estado civil (dúvida que hoje se reflete, justamente, no repensar da oposição entre natureza e cultura, que Latour e Serres compartilham com outros autores).

Em Latour, o cientificismo é associado à modernidade, que ele renega. Aí também com certa ambigüidade, pois ora a modernidade surge como uma realidade presente e, mesmo, ameaçadora, ora "jamais fomos modernos". Mas se jamais fomos modernos, por que tanta preocupação? Talvez aí igualmente se possa lançar mão da idéia de duplo-vínculo, mais positiva que a de ambigüidade: é como se o cão de Gregory Bateson simultaneamente rosnasse e abanasse a cauda para a modernidade. Afinal, embora a definição de modernidade segundo Latour sirva bem a seus propósitos, sua operacionalidade tem como ponto de apoio a relação da Ciência com a sociedade e a problemática da pureza em contraposição à mistura, ao lado de outras dicotomias (como fato e valor, mundo e representação etc.). O que acontecerá se tiver dela, também, uma definição mais abrangente? Continuará a renegá-la?

E como ficamos "nós", aqui embaixo, em relação à modernidade? Quem sabe se nos trópicos, onde sempre cultivamos as misturas, muito mais do que as purificações, podemos imaginar uma modernidade que, paradoxalmente, não realize uma ruptura em relação ao passado? Uma imaginação da modernidade mais próxima das suas práticas efetivas: ao invés de reduzir-se o oficioso ao oficial em nome da transparência, tratar-se-ia, então, do oposto. Até hoje, vimos essa ausência de ruptura como uma falta em relação a nossos sonhos revolucionários e aos discursos que compramos do Primeiro Mundo; mas nesta era de "segundos pensamentos" em relação à modernidade, quem sabe se não será, esse, um privilégio do subdesenvolvimento: a exploração de modernidades alternativas (Velho, no prelo) em relação aos discursos; bem diferente - mas talvez mais difícil — da tentação oposta (e sempre presente), de querer ser mais realista do que o rei, "congelando" a modernidade por meio de um ocidentalismo, justamente na época do seu paradoxal desencantamento. E afinal, essas possibilidades talvez estivessem presentes no alvor da modernidade; por exemplo, nos mencionados Maquiavel e Espinosa, uma concepção de tempo dobrado (como em Serres), permitindo enxergá-las mais próximas do que se costuma; sobretudo se não levarmos excessivamente a sério o discurso da modernidade triunfante. Tratar-se-ia, assim — em modo distinto ao de Latour - , menos de se desfazer do pacote inteiro da modernidade do que desfazê-lo. 
E afinal, será de fato tão difícil disputar o sentido da informação? Será preciso entregá-lo de mão beijada (inclusive, próximo a nós, entregar aos lingüistas e seu irrealismo), quando a comunicação é parte de um repertório tão mais rico, que eventualmente poderia incluir até o falar e fazer falar entre humanos e não-humanos de Latour? As razões de Latour para não utilizar Peirce (a sua associação a um paradigma da comunicação, cujas noções de índice e ícone seriam articuláveis, por sua vez, a uma ênfase na recepção, afim, ao que parece, da supracitada presentificação) serão convincentes? Não se estará, também aqui, levando demasiadamente a sério uma modernidade que supostamente nunca existiu? Isso tudo sem deixar de reconhecer que a posição que Serres, em contraste, personaliza, tende por vezes, de fato, no seu culto à criação, a cavar ainda mais fundo dentro do círculo de giz da hýbris do conhecimento: em Hominescências chega-se a demandar uma teoria geral dos sinais (note-se o contraste com a não-equivalência generalizada, sugerida por Latour), que englobaria todos os seres; e fala-se numa evolução do mundo na direção de um conhecimento de si mesmo, espécie de Gaia produzida-virtualizada pelos seres humanos tecnológicos (2001:135). Somos devedores de Latour, por apontar para esse círculo de giz do conhecimento, no próprio templo dos seus sacerdotes: a academia.

A propósito, no terreno da religião surge outra ambigüidade em Latour. Ele, que se põe contra as rupturas modernas, busca uma linguagem religiosa que atenda às demandas de hoje e que será necessariamente diferente das do passado - segundo ele, falidas. Porém essa falência, a se ver pelo que acontece entre nós, não é tão clara. Sem falar que também se deveria (ao contrário do que costuma ocorrer entre os analistas) distinguir discursos e práticas. As linguagens religiosas, na prática, apresentam-se vivas, às custas apenas de certa impressão de fundamentalismo, devido a alguns dualismos, que, por sua vez, desfazem outros (Velho 1997). Mas o próprio Latour já nos mostrou (Latour 2002c [1996]), como no caso do fatiche (combinação de fato e fetiche, também traduzido como fe[i]tiche), que, seguidamente, o fundamentalismo está mais nos olhos do observador, moderno. Entre nós, parecem vivas essas linguagens, a serviço de uma religiosidade da presentificação, da experiência, justamente como gostaria Latour (e William James); e do "Deus vivo", como gostam de dizer os pentecostais, na mesma direção. A linguagem tradicional, no caso, não está a serviço propriamente da tradição, no sentido da simples transmissão em cadeia (como demasiadas vezes a tratam antropólogos e teólogos). Talvez falte, aqui, mais atenção à recepção; como, aliás, pode ser também o caso quando se reduz a comunicação à transmissão de mensagens. Para dar um 
toque local: quando os camponeses no Brasil falam no "cativeiro", a riqueza de significados aí presentes, que são suscitados e postos a agir, não deve ser subestimada, pois eles, os camponeses, estão se reportando ao mesmo tempo ao cativeiro bíblico, à escravidão histórica abolida oficialmente no Brasil no final do século XIX e a situações presentes (Velho 1995). Mundo contínuo, tempo contínuo; ou tempo dobrado, amassado, como diria Serres. Quem sabe, mesmo, toda a linguagem religiosa não poderia ser tratada como Latour sugere para o caso dos fatiches - simultaneamente real e construída, em uma religião da qual Feuerbach poderia ser o apóstolo? Uma espécie de fatichismo generalizado.

Não é incomum ouvir de fiéis: "eu não vou poder rezar, se não entender Deus como uma pessoa". A pessoa, no caso, é um fatiche! Como também o texto. Por que, então, precisaria ser essa linguagem "atualizada" mais do que já o é por si mesma? A não ser como concessão à falta de imaginação moderna, ao mal-entendido da iconoclastia, tão bem descrita por Latour (2002c [1996]). Por que, depois de tudo, render-se a essa modernidade? Por que também render-se a uma concepção linear do tempo? A atualização da linguagem religiosa não precisaria ser mais do que a que se apresenta na própria dinâmica transformativa do sistema de relações — no fluxo contínuo das mediações, como quer Latour — mas não propriamente como uma tarefa nossa. Apostar nela talvez seja preferível a nos colocarmos no papel de fazedores de religião; ou, melhor ainda, também aqui deveríamos desfazer a oposição entre sujeito e objeto.

É bem verdade que a situação na Europa apresenta-se bastante próxima do que diz Latour, se é que lhe serve de condicionante. E talvez seja preciso estar fora da Europa para vê-la como exceção, e não como vanguarda, como às vezes transparece no próprio Serres. Estar fora da Europa para apreciar, devidamente, a carga de exotismo expressa na ideologia radical do laicismo francês, por exemplo. E, no entanto, mesmo assim, uma exceção a ser qualificada, como tem sido feito nos trabalhos de Grace Davie (2000), que mostra a religião bem mais viva do que nos relatos usuais, inclusive nos de Latour: afinal, os estádios de futebol, assim como as igrejas que Latour aponta em Jubiler, também estão se esvaziando; e isso não significa que estamos a presenciar o fim do futebol, apenas uma mudança nos modos pelos quais se expressam os aficionados. E sem falar do Islã, que - de novo, em um tempo dobrado - volta a ser parte da Europa, não podendo mais ser tratado como uma externalidade.

Na contramão dos esforços neo-esclarecidos para estabelecer um aggiornamento, um "diálogo" entre a ciência e a religião, Latour diz que montar esse palco já é uma impostura, sendo necessário, no caso, evitar re- 
conciliações precipitadas para não cair na armadilha cientificista. No texto aqui publicado, não é a informação duplo-clique que separa a ciência da religião, mas essa instigante inversão do senso comum, pela qual a religião trata do aqui e agora, ao passo que a ciência trata do invisível. Mas o que fazer diante de controvérsias concretas, como a da legislação sobre manipulação de embriões humanos, em que estão envolvidos conjuntamente cientistas, políticos e (Latour não costuma mencioná-los nesse tipo de contexto) religiosos, em um debate que não temos como evitar ou adiar? Ele já nos ensinou que as redes se caracterizam por sua heterogeneidade e que as incomensurabilidades são construídas. E por que não o seriam também, nesse caso? Ainda mais quando as redes acabam se cruzando? Não será isso uma rendição, ainda, a uma epistemologia, por mais diferente que se apresente, e um passo atrás em relação à ecologia política, às articulações e aos coletivos (Latour 2004 [1999])? Se é correto que Serres não deveria, por desprezo à política e às ciências sociais, manter intacta a Natureza, e se é correto, ainda, duvidar de um "contrato natural" que assim proceda (Latour 2004 [1999]:317), será que isso, por outro lado, nos autoriza a deixar tudo adiado para um mundo comum posto no futuro (2004 [1999]:92-99)? Como se faz a ponte entre o presente e esse futuro? Devemos ignorar por razões táticas o embate concreto, sob pretexto de que uma unificação apressada levará necessariamente água ao moinho da Ciência, mesmo quando o que (já) se está discutindo (inclusive no Brasil, onde temos na SBPC um belo exemplo de um espaço onde se disputa o estabelecimento de um fórum híbrido) é justamente a constituição ou não de uma assembléia ao menos parcialmente unificada? Não será possível, neste momento de crise, em que os consensos são substituídos pelos (des)acordos e em que todos aparentemente têm o seu cientista (bem como o seu médico), separar da Ciência uma parte dos cientistas?

E será, de fato, a multiplicação dos regimes de enunciação uma boa preparação para o mundo comum? Em que linguagem vamos nos entender? Apesar de Latour ser um tanto vago quanto à abrangência dessa linguagem, talvez se possa aplicar a ele a observação de Talal Asad a respeito da tentativa de Clifford Geertz de definir uma religião separada das práticas:

[...] there cannot be a universal definition of religion, not only because its constituent elements and relationships are historically specific, but because that definition is itself the historical product of discursive practices (Asad 1993:29).

É difícil não desconfiar de soluções que no seu detalhamento (por exemplo, com a atribuição de um papel-chave a economistas, como que 
convertidos a novas regras segundo o modelo paulino) minimizem os riscos (presentes) de uma contabilização generalizada (Latour 2004 [1999]:205210), contra a qual já nos alertou Marilyn Strathern com sua noção de audit culture (1999). E, para quem se pretende não-crítico e aparenta um relativo pragmatismo, não haverá nisso tudo certo excesso de separações (entre o novo e o velho), de suspensões, de regras e, enfim, certa aposta excessiva nas Constituições como totalidades irretocáveis? Não se tende a exagerar, assim, ao mesmo tempo, o que não se pode fazer agora e o que se poderá fazer depois, minimizando as misturas, as mudanças - que se dão imperceptível e gradualmente - e subordinando (de um modo que contradiz a linha de argumentação de Latour) a política a uma dinâmica que não é a sua?

Mas que não haja dúvidas: a obra em andamento de Bruno Latour constitui um sopro de renovação. Muito do que se poderia apontar como dificuldade do seu pensamento, talvez apareça assim devido ao fato de não se atentar devidamente ao mandamento de não "congelar imagens", para também aplicá-lo ao próprio fluxo do pensamento do autor; advertência, aliás, que bem fariam os antropólogos em observar com relação a si mesmos (e seus epígonos). Como ele próprio já afirmou (Latour 2004 [1999]), trata-se de valorizar a experimentação e as trajetórias de aprendizagem. Devem-se também, essas dificuldades de seu pensamento, ao fato de não se levar em conta o que há de estratégia nas suas afirmações. Estratégia que tem a ver com essa longa e dispersa nota de cautela em relação ao cientificismo (na qual, pelo viés da generalização de um princípio da precaução, nosso autor se identifica com o espírito - prático — da melhor antropologia) e com a aposta nos coletivos que não se compõem apenas de humanos. Mas tal estratégia tem a ver também com o reconhecimento de Deus, ou pelo menos de seu lugar - uma questão que vem sensibilizando, hoje, muitas figuras do mundo da filosofia, de Derrida a Charles Taylor e Gianni Vattimo, sem falar do próprio Serres e que está associada tanto à obsolescência do que Latour considera o falso dilema realismo-construtivismo, quanto a algum espanto diante do niilismo que se produziu nos últimos séculos (e seus efeitos), e ainda, pode-se supor, ao fascínio subliminar de certas presenças e afetações (como a do Islã) nesse mundo que nos engloba.

Em Jamais Fomos Modernos, Latour diz a certa altura:

Nosso passado começa a mudar. Enfim, se jamais tivéssemos sido modernos, pelo menos não da forma como a crítica nos narra, as relações tormentosas que es- 
tabelecemos com as outras naturezas-culturas seriam transformadas. O relativismo, a dominação, o imperialismo, a má fé, o sincretismo seriam todos explicados de outra forma, modificando então a antropologia comparada (1994 [1991]:16).

Mesmo havendo Latour substituído posteriormente o princípio da simetria, que inspirava essas considerações, por um respeito igualitário (Latour 2004 [1999]:348), permanece aí, sem dúvida, uma chave interessante. Sobretudo para os cá de baixo, como nós. Chave, inclusive, para o tema dos regimes de enunciação. Assim, "jamais fomos modernos" apenas da forma como a crítica narra. Se não é assim, como, de fato, explicar o diálogo entre Latour e Serres, que proclama estarmos vivendo, graças à ciência, o nascimento de um novo mundo "sem nenhuma relação com qualquer outro mundo, desde o começo dos homens e das sociedades" (2003 [2001]: 275)? E como falar até em uma nova Constituição e na produção do melhor dos mundos possíveis (Latour 2004 [1999]) — ainda que, em Latour, essas novidades tenham também o sentido de uma reconciliação com o passado e com outras naturezas-culturas? A importância de se constranger a modernidade não está no terreno da ciência, mas em nos aproximar das demais naturezas-culturas, em relação às quais sempre - inclusive na antropologia - nos consideramos superiores. Latour sabe que o poder depende de uma atribuição: no fundo, não é que o rei da modernidade duplo-clique não exista, mas a decretação de sua nudez é a pedra de toque necessária para proceder ao necessário descongelamento das imagens.

Resta, porém, um problema: esse descongelamento precisa também aplicar-se às imagens sobre essas supostamente outras naturezas-culturas. Latour pretende fazê-lo pelo estabelecimento do chão comum da não-modernidade (ou do ecológico), o que é bem diferente da tolerância do relativismo cultural às diferenças, pois este renuncia à busca de um chão comum. Mas se efetivamente estivermos interessados nos nativos e nas suas respostas, sem enquadramento prévio em nossos esquemas, é preciso questionar, por um lado, até que ponto o não-moderno deles, em todos os casos, corresponde ao de Latour (indagação pragmática que de modo algum precisa implicar em culturalismo). Por outro lado, como nada disso foi combinado com eles, e uma vez que podem estar picados (e muitos de fato já o foram) pelos insetos portadores da modernidade globalizada (a globalização não sendo tomada, aqui, como necessariamente reducionista e prematura), será também preciso ver se esses nativos se reconheceriam nesse mesmo terreno. Até porque, nesse caso, temos que a modernidade - que, assim como os objetos-mundo de Serres (e os mitos), só se apresenta por intermédio de suas versões (essas sim, eventualmente constrangíveis) - 
talvez, de fato, não possa ser possuída, não podendo, portanto (e sobretudo), ter a sua inexistência decretada. Cá embaixo - e pode ser essa diferença a responsável por algumas das dúvidas que eram colocadas acima sobre a postergação dos assuntos atinentes ao mundo comum - a debilidade (relativa) da Ciência tende a provocar uma tensão entre os fundamentalistas da Ciência (mais realistas do que o rei) e a pujança (relativa) de fóruns híbridos, que é sintomática, talvez, do que já foi mencionado acima como modernidades alternativas.

Chama atenção, em Latour, não haver lugar consistente para o terceiro gênero de conhecimento, segundo Espinosa: o que trata das relações das coisas singulares com a totalidade. As redes e, mesmo, seus desdobramentos, como os rizomas (Crawford 1993) e attachements, bons e maus (Latour 2000) são mais claramente associáveis ao segundo gênero, o das noções comuns, relações necessárias e afetações (no caso, em continuação ao primeiro gênero, o da imaginação). Apesar da sua oposição à Natureza, cara ao filósofo, Espinosa está presente para Latour até na qualificação do seu livro sobre os micróbios (2001[1984]) como um "tratado científico-político" - inspirado, como o de seu predecessor seiscentista, pela questão da democracia, mas agora em um tempo de "guerras de ciência". No entanto, sem nomeá-los, ele parece privilegiar o segundo gênero em relação ao terceiro, que para Espinosa constituiria uma culminância que não é estranha à abdicação de tudo o que se sabe, preconizada por Serres. E isso em uma verdadeira militância contra o discurso do holismo (inclusive no terreno da religião, onde como vimos, prevaleceria a presentificação). É o que transparece na sua crítica à Naturpolitik dos ecologistas, que estaria invariavelmente distante - e, de novo, nos vemos diante desse tipo de contraposição - da prática desses mesmos ecologistas, que depende de lugares, situações e eventos particulares (Latour 2004 [1999]). É como se esse terceiro gênero fosse por demais místico e espiritual, incompatível com uma postura pragmatista e denegador das articulações concretas. Mas, supondo que assim seja (o que mereceria maior discussão), o que ocorreria se já houvesse, enfim, surgido a sua justificativa material, não como ponto de partida, mas como ponto de chegada (totalização)? Não estaremos, novamente, diante de realidades presentes que Latour, embora seguindo a mesma linha de raciocínio (no caso, a da totalização), coloca no futuro? A cautela, então, não se tornará debilitante? Pois Serres, em Hominescências, decreta o fim das redes e a instauração de um novo espaço, topológico, sem distância mensurável e que permite uma ubiqüidade generalizada que sepulta o ser-aí heideggeriano e o aqui e agora (latouriano?), em favor do que já denominara ser-por-todo-o-mundo (être-partout), que invade a 
ontologia (Serres 1992:40). Seriam eventos provocados pelos novos objetos-mundo: o computador portátil e o telefone celular. Objetos-mundo aos quais, pelo menos a meio-caminho, alguns de nossos índios poderiam acrescentar o gravador e a filmadora. Esses mesmos índios que, se consultados (como preveria a Constituição não-moderna proposta por Latour, e ao contrário do que ele supõe para os não-humanos e sugere para eles próprios (2004 [1999]:347)), talvez não se revelassem interessados em ter cientistas (ou filósofos) como porta-vozes, papel que no final das contas ainda pareceria considerável, mas que vai de encontro à proposta democrática do autor, ou ao menos revela suas contradições latentes. Unilateralidades à parte (afinal, não parece haver, em princípio, incompatibilidade entre redes e espaço topológico), seria crucial verificar as implicações disso tudo; não se devendo, ainda, negligenciar o aqui e agora de segundo grau, recriado a partir do global.

Portanto, esse diálogo deve continuar. Mas para que isso se dê, ele precisará talvez ser ampliado, rompendo várias barreiras que, ao menos parcialmente, ainda separam tradições intelectuais diversas. Evitando o congelamento das imagens (frame-freezing), na expressão de Latour, poderíamos então encetar diálogos mais produtivos, em que as questões postas até aqui, e muitas outras, encontrariam espaço para propagar-se.

Otávio Velho é pesquisador emérito do Departamento de Antropologia/Museu Nacional/UFRJ. E-mail: <otaviovelho@terra.com.br> 


\section{Referências bibliográficas}

ASAD, Talal. 1993. "The construction of religion as an anthropological category". In: . Genealogies of religion: discipline and reasons of power in christianity and Islam. Baltimore and London: The Johns Hopkins University Press. pp. 27-54.

CRAWFORD, Hugh T. 1993. An interview with Bruno Latour. Baltimore: The Johns Hopkins University Press/ Society for Literature and Science.

DAVIE, Grace. 2000. Religion in modern Europe: a memory mutates. New York: Oxford.

LATOUR, Bruno. 1994 [1991]. Jamais fomos modernos: ensaio de antropologia simétrica. Rio de Janeiro: Editora 34.

. 2000. "Factures/fractures: de la notion de réseau à celle d'attachement". In: A. Micoud e M. Peroni (orgs.), Ce qui nous relie. La Tour d'Aigues: Éditions de l'Aube. pp. 189-207.

. 2001 [1984]. Pasteur: guerre et paix des microbes suivi de Irréductions. Paris: La Découverte.

. 2002a. Jubiler ou les tourments de la parole religieuse. Paris: Les Empêcheurs de Penser en Rond.

. 2002b. La fabrique du droit: une ethnographie du Conseil d'État. Paris: La Découverte.

. 2002c [1996]. Reflexão sobre o culto moderno dos deuses fe(i)tiches. Bauru: EDUSC.
. 2004 [1999]. Politiques de la nature: comment faire entrer les sciences en démocratie. Paris: La Découverte.

. s/d. Si l'on parlait un peu politique (versão final para publicação em Politix).

SERRES, Michel. 1992[1987]. Le contrat naturel. Paris: Flammarion. . 1999 [1992]. Luzes: cinco entrevistas com Bruno Latour. São Paulo: Unimarco. . 2003 [2001]. Hominescências: o começo de uma outra humanidade? Rio de Janeiro: Bertrand Brasil.

STRATHERN, Marilyn. 1999. "A avaliação no sistema universitário britânico". Novos Estudos Cebrap, 53:15-32.

VELHO, Otávio. 1995. "O cativeiro da besta-fera". In: . Besta-fera: recriação do mundo. Rio de Janeiro: Relume Dumará. pp. 13-43. . 1997. "Globalização: antropologia e religião". Mana. Estudos de Antropologia Social, 3(1):133-154. no prelo. Mais realistas do que o rei: do ocidentalismo das elites às modernidades alternativas (título provisório). 